\title{
Editorial
}

\section{Architecture as a generator of health and well-being}

\author{
Stefano Capolongo \\ ABC Department, Polytechnic University of Milan, Italy
}

With the approval of Article 32, first paragraph of the Italian Constitution in $1948,{ }^{1}$ health is accepted and safeguarded by the Republic as a fundamental right of every citizen which also plays a collective interest. The basis of this statement lies in the undeniable observation that only a country whose population enjoys a significant level of health can develop cultural, professional, research and economical activities whose common result is wealth and wellbeing.

Designing places of living should not only take into account functional spaces for individual and collective needs, but should also protect health, as humans spend $80 \%$ of their time in built spaces. Paradoxically, we could state that an architect has a key role in protecting health more than a doctor. ${ }^{2}$

In the discipline of Architecture there are many historical stages in which architects and planners have contributed to the improvement of living conditions when inspired by an ethic and social vision. ${ }^{3}$

Starting from the Roman city planning innovation, health awareness about places of living and work has grown over time. The first great paradigm took place during the plague Era, where the living culture had to react for not being overwhelmed by the message of death. Lazarettos were constructed in addition to renovations of the design of the houses and public spaces. After the Industrial Revolution crisis, the Nineteenth Century city was renewed thanks to the work of architects, engineers and enlightened hygienists. Garden cities and social housing were built, entire neighborhoods devastated by tuberculosis were renewed up to the emergence of rationalist architecture. Recently, in the culture of sustainability, no architectural project can avoid the involvement of medical sciences along with psychological, anthropological and social contributions, in order to reach the formulation of healthy city concept.

These achievements can be found within the context of national and international legislative and regulatory framework, in which there is a well-established system of indicators aimed to ensure the minimum hygiene requirements of architecture. ${ }^{4}$

Combination of design aspects, use of materials and the distribution of the spaces are merged along with many others in the Healthy cities project of the WHO/Europe. Currently, 90 cities are members of the WHO European Healthy Cities Networks and 30 national Healthy Cities Network in the European Region have involved in the project the amount of 1400 cities. $^{5}$

Health has often stimulated critical reflections and experimental proposals within the architectural discipline. If we consider the works of Alvar Aalto, Franco Albini, Ignazio Gardella and the theories of Le Corbusier, we can found that a special attention has been given to the psychological and physical well-being. Therefore, we can say that topics concerning health have always been inspiring and stimulating technological innovation of both products and processes at different scales: territorial and urban development projects as well as architectural and interior design.

The role of an architect as a promoter of health should be played in designing living and work and leisure spaces, in addition to those specifically designed to restore and protect public health. ${ }^{6}$ His expertise as an architect might be completed by skills in the fields of materials, engineering, technological systems, urban planning as well of medicine and, in particular, of public health. This integration can be developed within the design process, but above all, it must be strengthened during the education of the architect. The relationship between Architecture and Engineering already exists in three Italian Polytechnics (Milan, Turin and Bari) and in many other universities where the two schools coexist yet. The collaboration is less obvious with the medical world and schools. It is true that in some cases biomedical engineers are already working jointly and in some schools there are courses of engineering focused on the management of health facilities. Although Environmental Health is already taught in Milan, Rome, Genoa, Sassari, further widespread integrations in Architecture schools are needed to increase the awareness about the role of future architects as guarantors and guardians of the Public Health of a community.

Correspondence: Stefano Capolongo, Department of Architecture, Built Environment and Construction Engineering, Polytechnic University of Milan, via E. Bonardi 3, 20133 Milano, Italy.

Tel. + 39.02.2399.5140.

E-mail: stefano.capolongo@polimi.it

Received for publication: 10 April 2014.

Accepted for publication: 10 April 2014.

CCopyright S. Capolongo, 2014

Licensee PAGEPress, Italy

Journal of Public Health Research 2014; 3:276

doi:10.4081/jphr.2014.276

This work is licensed under a Creative Commons Attribution NonCommercial 3.0 License (CC BY-NC 3.0).

\section{References}

1. Italian Constitution, Art 32. (G.U. 27 december 1947, n. 298, E.S.)

2. Capolongo S, Buffoli M, Oppio A, Rizzitiello S. Measuring hygiene and health performance of buildings: a multidimensional approach. Ann Ig 2013;25:151-7.

3. Capasso L., Schioppa F.S. 150 anni di requisiti igienico-sanitari delle abitazioni in Italia. Ann Ig 2012;24:207-16.

4. Buffoli M, Capolongo S, Cattaneo M, Signorelli C. Project, natural lighting and comfort indoor. Ann Ig 2007;19:429-41. [Article in Italian].

5. Capolongo S, Battistella A, Buffoli M, Oppio A. Healthy design for sustainable communities. Ann Ig 2011;23:43-53. [Article in Italian].

6. Faroldi E, Vettori MP. La casa della ricerca. The house of research. Centro Ricerche Chiesi. Parma, Verona: Electa; 2012. 